\title{
Flow Cytometry Analysis of Pro- and Anti-inflammatory Cytokines in Alzheimer's Disease Model Treated with Ginkgo biloba
}

\author{
Salgado ASI ${ }^{1}$, Eltchechem $\mathrm{CL}^{2}$, Kerppers II*, Silva Pereira $\mathrm{MC}^{2}$, Suckow $\mathrm{PT}^{2}$, Gomes $\mathrm{JC}^{2}$, Hosni $\mathrm{AP}^{2}$, Miri $\mathrm{AL}^{2}$ and Carraro $\mathrm{E}^{3}$ \\ ${ }^{1}$ Manual and Postural Therapy School, Londrina State University, Londrina, Brazil \\ ${ }^{2}$ Neuroanatomy and Neurophysiology Laboratory, Midwest State University, Guarapuava, Brazil \\ ${ }^{3}$ Immunology Laboratory, Midwest State University, Guarapuava, Brazil
}

\begin{abstract}
Alzheimer's disease $(A D)$ is a neurodegenerative disorder that accounts for two-thirds of dementia cases in the elderly and may show preliminary symptoms for decades. The dry leaf extract of Ginkgo biloba (EGb 761) has been used as a dietary supplement for the treatment of mental disorders in both humans and animals.

Objective: This study examined the immunological effect of EGb 761 in the treatment of rats with experimental Alzheimer's disease.

Methodology: The sample consisted of 40 Wistar male rats, weighing 200-250 grams and divided into 4 groups: 21 days control, 42 days control, 21 days treated, and 42 days treated. Stereotaxic surgery was performed with the coordinates of $\mathrm{AP}=-3.12, \mathrm{ML}=3.6 \mathrm{~mm}$, and $\mathrm{DV}=3.0$; animals were undisturbed for 5 days after surgery and brought back to stereotaxic to be injected with $2 \mu \mathrm{L}(1 \mathrm{mg})$ of Beta-amiloide25-35 toxin in the CA1 region. Animals in the treated group received $100 \mathrm{mg} / \mathrm{kg}$ of EGb 761 by gavage. Animals were euthanized at 21 and 42 days; $1 \mathrm{ml}$ of blood was collected for the flow cytometry analysis of pro- and anti-inflammatory cytokines.
\end{abstract}

Results: A significant difference was observed between the pro-inflammatory cytokines: IL-6 and IFN- $y$ showed low levels of concentration compared to IL-2 and TNF- $\alpha$. The IL-4 and IL-10 anti-inflammatory cytokines were present at high levels of concentration in the 21 and 42 days treated groups.

Conclusion: EGb 761 was effective in reducing serum levels of pro-inflammatory cytokines, thereby promoting a reduction in the inflammatory process generated by $A D$.

Keywords: Alzheimer's disease; Gingko biloba; Cytokines; Memory; Flow cytometry; Rats

\section{Introduction}

Alzheimer's disease (AD) is a neurodegenerative disorder that accounts for two-thirds of dementia cases in the elderly and may show preliminary symptoms for decades [1,2]. Dementias are diseases mainly characterized by symptoms related to the progressive decline in memory, attention, concentration, and reasoning as well as personality mood, and behavior alterations [3]. In addition to difficulty with attention and verbal fluency, cognitive functions such as the visuospatial skills, the ability to make calculations, and the ability to use common objects and tools, deteriorate with disease progression [4].

Pathological studies among AD demonstrate neuronal/synaptic losses together with amygdaloidal deposition, tangled neurofibrils, microglia, and astrocytes activation that promote direct damage at synapses and stimulate inflammatory response $[5,6]$. The inflammatory response promotes alterations in neuronal ionic homeostasis and oxidative stress involving the neuronal and synaptic function, which results in a deficit in neurotransmission and cognitive symptoms [7-9].

According to De La Torre [10], the involvement of cerebral vascular dementia is frequent in patients with AD. From an epidemiological perspective, there is a decline in the cerebrovascular function and a reduction in the cerebral blood flow and metabolism in individuals with $\mathrm{AD}$. Pharmacological interventions for diseases related to dementia are, in part, limited; thus, alternative therapies using natural extracts represent additional options for patients suffering from this type of diseases [11,12]. The dry leaf extract of Ginkgo biloba (EGb 761) has been used as a dietary supplement for the treatment of mental disorders in humans and animals [13-15]. Its extract contains approximately $24 \%$ of flavonoids, a known potent antioxidant [16]. A recent review study by Yang et al. [12] showed that Ginkgo biloba supplements help $\mathrm{AD}$ patients with cognitive symptoms.

Bastianetto et al. [16] showed that Ginkgo biloba has a protective function on hippocampus cells for the $\beta$-Amiloid peptide $(A ß)$ induced toxicity. Freitas et al. [17] point out the toxicity of infectious agents, aluminum, reactive oxygen species (ROS), and neurotoxic amino acids as agents of AD. Allen and Tresini [18] report that increased levels of reactive oxygen species (ROS) above buffer capacity and the increased enzyme activity required to modulate the levels of these species result in potentially cytotoxic oxidative stress that can damage DNA, RNA, proteins, and phospholipids responsible for membrane integrity and lead to cell death.

Because of positive evidence regarding the effects of the Ginkgo biloba extract (EGb 761) on the central nervous system, this study examined its immunological effect in the treatment of rats with experimental Alzheimer's disease. The Introduction section should include the background and aims of the research in a comprehensive manner, for the researchers.

*Corresponding author: Ivo Ilvan Kerppers, Neuroanatomy and Neurophysiology Laboratory, Midwest State University, P.O.: 85040-080, Guarapuava, Brazil, Tel: +55 042-3621-1090; E-mail: ikerppers@hotmail.com

Received March 28, 2017; Accepted April 12, 2017; Published April 22, 2017

Citation: Salgado ASI, Eltchechem CL, Kerppers II, Silva Pereira MC, Suckow PT et al. (2017) Flow Cytometry Analysis of Pro- and Anti-inflammatory Cytokines in Alzheimer's Disease Model Treated with Ginkgo biloba. J Biosens Bioelectron 8 241. doi: $10.4172 / 2155-6210.1000241$

Copyright: () 2017 Salgado ASI, et al. This is an open-access article distributed under the terms of the Creative Commons Attribution License, which permits unrestricted use, distribution, and reproduction in any medium, provided the original author and source are credited. 


\section{Materials and Methods}

\section{Sample calculation}

Sample Size: The calculation of the sample size (n) was performed according to Vieira and Hossne [19] and Pereira [20], and based on the study by Freir and Costello [21], who showed a prevalence level of $99 \%$ in mice with Alzheimer's disease after the application of the Beta-Amiloid 25-35 peptide (Sigma-Aldrich), significance level (1.96), and the accuracy required for estimation (0.1), according to the CEUAUNICENTRO committee's approval number 018/2014.

\section{Sample}

The samples consisted of 50 Rattus norvegicus animals, Wistar strain, weighing between 200 and 250 grams. The animals were divided into four groups:

Control 21 group (C21): Composed of 10 animals with induction of senile plaques in the CA1 region and not treated; euthanized on day 22;

Control 42 group (C42): Composed of 10 animals with induction of senile plaques in the CA1 region and not treated; euthanized on day 43;

Treated 21 group (T21): Composed of 10 animals with induction of senile plaques in the CA1 region and treated with Ginkgo biloba (EGb 761 ) at the concentration of $100 \mathrm{mg} / \mathrm{kg}$, diluted in $1 \mathrm{ml}$ of drinking water, and administered by gavage only on day 21 ; euthanized on day 22;

Treated 42 group (T42): Composed of 10 animals with induction of senile plaques in the CA1 region and treated with Ginkgo biloba (EGb 761 ) at the concentration of $100 \mathrm{mg} / \mathrm{kg}$, diluted in $1 \mathrm{ml}$ of drinking water, and administered by gavage from day 21 to 42 ; euthanized on day 43;

Normal group (GN42): Composed of 10 animals without induction of senile plaques in the CA1 region and not treated; euthanized on day 43.

\section{Experimental surgery}

The animals underwent stereotaxic surgery when cannulas were implanted into the hippocampal region and directed to the CA1 unilateral area following the coordinates of $\mathrm{AP}=-3.12 \mathrm{~mm}, \mathrm{ML}= \pm$ $3.6 \mathrm{~mm}$, and DV=3.0 $\mathrm{mm}$ and considering the bregma as a reference with lambdoid and bregmatic sutures in the same horizontal plane. Tramadol hydrochloride was used for analgesia at the dose of $10 \mathrm{mg} /$ $\mathrm{kg}$, every 12 hours, and intramuscularly for 7 (seven) days [22].

\section{Surgical procedure for $A \beta$ 25-35 (A $\beta-25-35)$ inoculation}

The protein $A \beta-25-351 \mathrm{MG}$ was acquired from the Sigma-Aldrich company, diluted to $0.1 \mu \mathrm{l}$ of DMSO, and $0.9 \mu \mathrm{l}$ of distilled water was added. It was then stored for 72 hours in a refrigerator at 4 degrees Celsius for incubation.

The animals were anesthetized intra-abdominally with a solution in the proportion of $80 \mathrm{mg} / \mathrm{kg}$ of Hydrochloride Ketamine (Ketamine, $10 \mathrm{ml}$ bottle) to $15 \mathrm{mg} / \mathrm{kg}$ of Hydrochloride Xylazine (Dopaser, 10 $\mathrm{ml}$ bottle) and taken to a stereotaxic apparatus (David Kopf, EUA), where their heads were fixed by the temporal bone and the upper incisors. Cannulas were made with $30 \times 09$ needles ( $5 \mathrm{~mm}$ long), implanted in the hippocampal region and directed to the CA1 area of the hippocampus, according to the stereotaxic coordinates in the atlas by Paxinos and Watson [23]. The stereotaxic coordinates used were the following: $\mathrm{AP}=-3.12 \mathrm{~mm} ; \mathrm{ML}= \pm 1.8 \mathrm{~mm}$ and $\mathrm{DV}=2.8 \mathrm{~mm}$, using bregma as a reference and the lamboid and bregmatic sutures on the same horizontal plane. After the implants were put in place, the cannulas were fixed in the calvaria using a self-curing acrylic prosthesis. Stainless steel wire was inserted in order to prevent occlusion of the cannula. A screw was placed in the anterior section of the skullcap to fix the wire. The animals were allowed to rest for five days and were then anesthetized once again and taken for stereotactic processing. Using a Hamilton syringe, they received $2 \mu$ of the peptide A $\beta$ 25-35 (Sigma-Aldrich) in the CA1 region of the hippocampus, as described by Freir and Costello [21]. Injected with $0.1 \mu \mathrm{l}$ per minute (with a total time of 20 minutes), thereby avoid backflow and allows the toxin being absorbed into the brain parenchyma (Figure 1).

\section{Study characterization}

The animals were undisturbed for five days after surgery and subsequently received the Beta-Amiloid 25-35 peptide (SigmaAldrich) through a Hamilton syringe in the hippocampal CA1 region as described by Freir and Costello [21]. Animals rested for 21 days after the intracerebral injection. One animal from each group was sacrificed, and their brains were analyzed to confirm the presence of senile plaques (Figure 2).

\section{Cytokines determination}

One milliliter of blood was collected from each animal. Blood was maintained in a water bath for 15 minutes, and centrifuged at $300 \mathrm{~g}$ for 5 minutes at $18^{\circ} \mathrm{C}$. After centrifugation, the supernatant (serum) was stained for the detection of IL-2, IL-4, IL-6, TNF- $\alpha$, and interferongamma (IFN- $\gamma$ ) using the BD $^{\text {tw }}$ Cytometric Bead Array Mouse Th1/Th2 Cytokine kit (Becton Dickinson, USA) according to the manufacturer's instructions; these samples were Analyzed in a $\mathrm{BD}^{\mathrm{ix}}$ Accuri C6 Flow Cytometer (Becton Dickinson, USA).

The theoretical detection limit for each cytokine using the $\mathrm{BD}^{\text {tax }}$ Cytometric Bead Array Mouse Th1/Th2 Cytokine Kit is defined as the concentration that corresponds to two standard deviations above the fluorescence average of

30 negative control replicates $(0 \mathrm{pg} / \mathrm{ml})$. These limits were: IL$2=0.1 \mathrm{pg} / \mathrm{ml} ; \mathrm{IL}-4=0.03 \mathrm{pg} / \mathrm{ml}, \mathrm{IL}-6=1.4 \mathrm{pg} / \mathrm{ml}, \mathrm{IFN}-\gamma=0.5 \mathrm{pg} / \mathrm{ml}, \mathrm{IL}-$ $10=16.8 \mathrm{pg} / \mathrm{ml}$, and TNF- $\alpha=0.9 \mathrm{pg} / \mathrm{ml}$. The readings were manually performed through the acquisition of 10,000 events in each sample. Flow cytometry data were analyzed in the FCap 3.0 Array software (Becton Dickinson, USA) and results were plotted in graphs showing averages and standard deviations.

\section{Water maze}

The maze is located in a $3 \times 3 \mathrm{~m}$ room and consists of a circular fiberglass pool, approximately $1.80 \mathrm{~m}$ in diameter and $43 \mathrm{~cm}$ height containing water at $25^{\circ} \mathrm{C}$ at the level of $30 \mathrm{~cm}$ deep. This pool is divided into four imaginary quadrants named NW (northwest), SW (southwest), NE (northeast), and SE (southeast). A circular acrylic platform ( $15 \mathrm{~cm}$ in diameter) is placed at $2 \mathrm{~cm}$ below the water level. The pool has no track or internal marks, but there are stable visual tracks outside the labyrinth, labeled in blue, yellow, and red that serves as a reference for the animal to locate the platform. The rat's ability to locate the platform depends on the development of a cognitive spatial map of the environment in the animal's brain. A television camera with angular lens was fixed on the ceiling, directly above the pool, to record the tests. All tests were performed at the same time of day with the same room temperature associated with the water temperature [24].

\section{Behavioral and locomotor measurement}

The Open Field Test provides simultaneous measurements of 


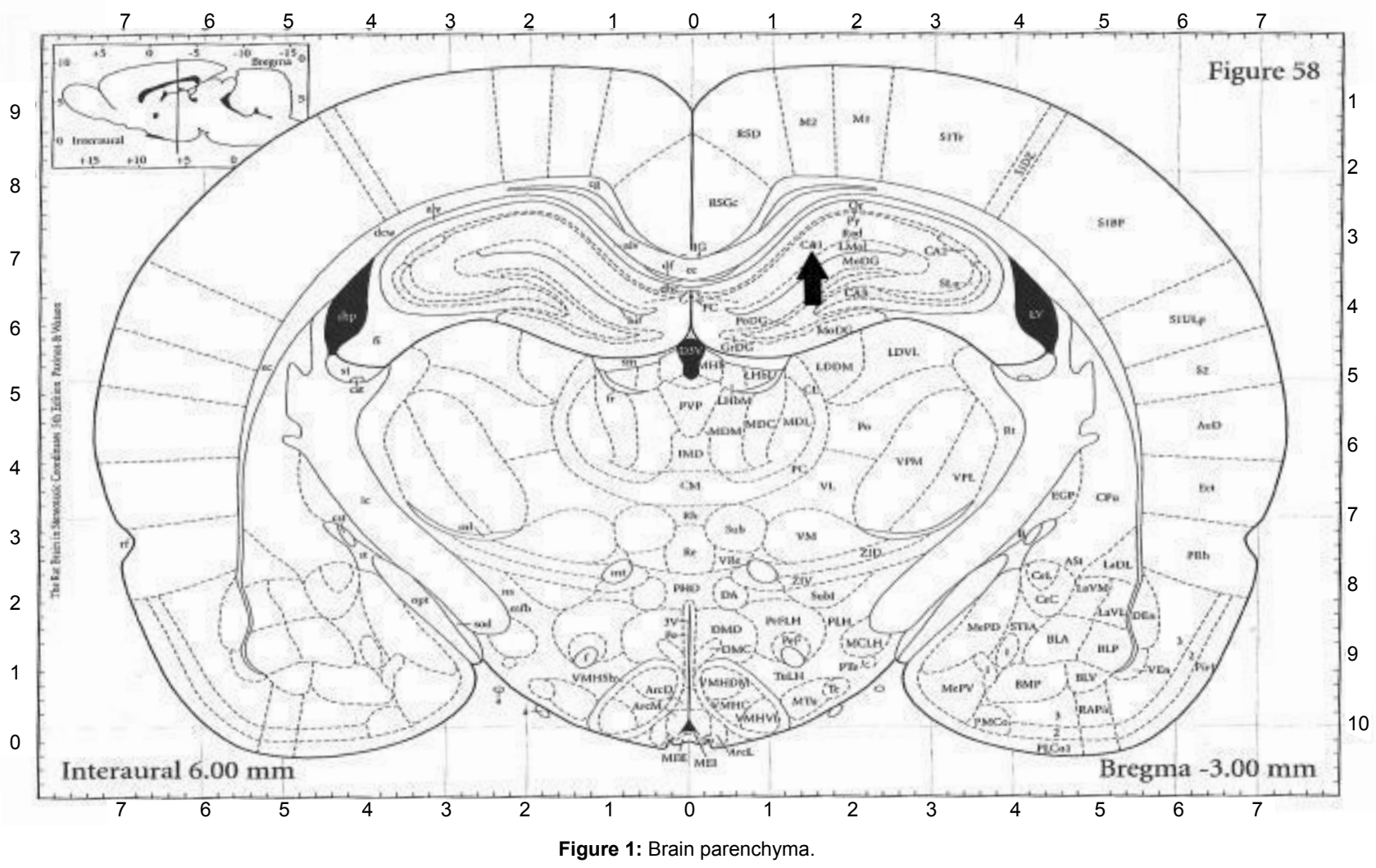

locomotion, exploration, and anxiety [25]. To conduct the test, the animals were individually placed in the center of an arena and exposed to the Open Field for a period of 5 minutes, during which time their behavior was filmed. The etiological analysis of their behavior assessed the following: the frequency and duration of walking, standing, and grooming; and the number of fecal boli. The number of rectangles covered by four paws corresponded to the locomotor measurement. Standing was classified as animals solely on hind paws. Grooming was classified as movements of front paws along the head or body. Fecal boli were counted after the animal was removed from the arena. The arena's floor was cleaned with alcohol and extensively dried through air circulation after each rat.

\section{Euthanasia}

The animals were anesthetized with $80 \mathrm{mg} / \mathrm{kg}$ of ketamine and $15 \mathrm{mg} /$ $\mathrm{kg}$ Xylazine; they received $1 \mathrm{ml}$ of a lethal dose of thiopental $(100 \mathrm{mg} / \mathrm{kg})$ intraperitoneally after the verification of their anesthetized state.

\section{Histology}

Brains were collected from euthanized animals; they were cut near the cannulas' path and placed in $15 \%$ formalin. The cuts were embedded in paraffin, sliced 2 microns thick, and stained with haematoxylin and eosin (H.E.) for verification of the presence of senile plaques. Although animals that did not have these characteristics would not be further evaluated, all animals evaluated at this stage showed the presence of senile plaques.

\section{Statistical analysis}

The Graph Pad 6.0 and Origin 8.0 software were used for graphic construction and data analysis, respectively. The Shapiro-Wilk test was used to verify sample normality, and the Kruskal-Wallis test, with the Dunn's post-test at $\mathrm{p}<0.05$, was used in the analysis of samples showing normality.

\section{Results}

Numerous alterations were observed between the control and treated groups in the histological analysis. The control group showed intense gliosis, reactive neurons associated with intense picnosis, malacia diffuse areas, multiple fibrotic astrocytes, hyperplastic and hypertrophic ependymal cells with perivascular astrocytes (Figure 2a). Intense vacuolation of gray substance with multifocal hypertrophic motor axons associated with intense spongiosis and malacia, and presence of hypertrophic astrocytes with diffuse spongiosis and diffuse senile plaques were observed in the treated group (Figure $2 b$ ).

Figure 3 shows the behavior of animals in relation to locomotion in the Open Field and Morris Water Maze tests. Rats treated with EGb 761 showed a greater range of locomotion than the control groups. The T21 and T42 averages after treatment with Ginkgo biloba were 1,125 \pm $857.1 \mathrm{~cm}$ and $1,115 \pm 459.6 \mathrm{~cm}$, respectively, compared to C21 and C42 with averages and standard deviations of $899.5 \pm 363.2 \mathrm{~cm}$ and 907.2 $\pm 96.12 \mathrm{~cm}$, respectively. The analysis showed statistically significant differences between these results with values of $\mathrm{p}=0.0059$ and $\mathrm{p}=0.0078$.

Figure 4 shows the results for pro-inflammatory interleukins. The levels of TNF- $\alpha$ were high in the C21 and C42 groups, with the values of $2,663 \mathrm{pg} / \mathrm{ml}$ and $2,097 \mathrm{pg} / \mathrm{ml}$, respectively; $1,009 \mathrm{pg} / \mathrm{mL}$ and 935.9 $\mathrm{pg} / \mathrm{ml}$ in T21 and T42 groups, respectively; and $53,879 \mathrm{pg} / \mathrm{ml}$ in GN42 group. The IL-2 levels were $2,533 \mathrm{pg} / \mathrm{ml}$ and $2,226 \mathrm{pg} / \mathrm{ml}$ in the $\mathrm{C} 21$ and C42 groups, respectively; $1,168 \mathrm{pg} / \mathrm{ml}$ and $869 \mathrm{pg} / \mathrm{ml}$ in the T21 and T42 groups, respectively; and $16,89 \mathrm{pg} / \mathrm{ml}$ in $\mathrm{N} 42$ group. The difference in 
IL-2 levels between the C21 and T42 groups was statistically significant. The average values for IL- 6 showed significance between the T42 and C21 groups. The same applies to the INF-y values showed statistical difference between the C21 and T42 groups. GN42 group with value of $10,52 \mathrm{pg} / \mathrm{ml}$ for IFN-y.

Figure 5 shows the concentration levels of Interleukin 4, an antiinflammatory mediator. The averages were $3,488 \mathrm{pg} / \mathrm{ml}$ and $3,085 \mathrm{pg} /$ $\mathrm{ml}$ in the C21 and C42 groups, respectively, 2,168 pg/ml and 2,357 pg/ $\mathrm{ml}$ in the T21 and T42 groups, respectively, and $16,10 \mathrm{pg} / \mathrm{ml}$ in GN42. The average values for IL- 4 showed significance between the T42 and

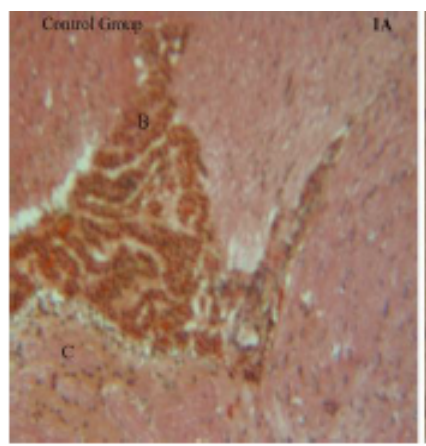

Figure 2a: Photomicrograph of the region where the $\beta$-amyloid toxin was injected.

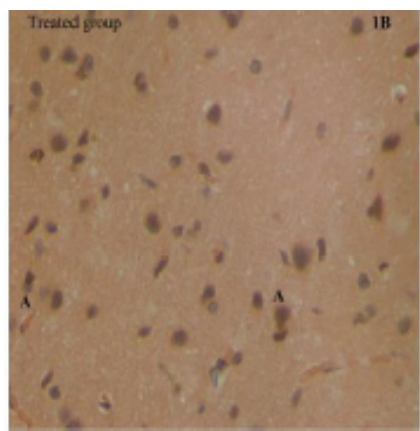

Figure 2b: Presence of senile plaques and some neurofibrillary aspects.
C21 groups. The same applies to the values of IL-10 which showed statistical difference between the $\mathrm{C} 21$ and $\mathrm{T} 42$ groups.

\section{Discussion}

The results show some neuronal alterations in the histological samples. The presence of reactive neurons (hypertrophic) is observed in both groups; reactive astrocytes have reduced ability to scavenge reactive oxygen species (ROS). This leads to a significant increase in free radicals and various species of ROS, rendering astrocytes vulnerable to metabolic and mitochondrial alterations and favoring the production of oxidative stress. The production of pro-inflammatory cytokines is favorable under these conditions as observed in the C21 group (without EGb 761 treatment), which shows high concentration levels. In the other groups, the effects of the EGb 761 extract influenced the control of pro-inflammatory cytokines.

Ni et al. [26], Bastianetto et al. [16] suggested that EGb 761 could attenuate apoptosis induced by A $\beta 25-35$. Chen and Herrup [27], demonstrated that cytotoxicity in neural cells is induced in the presence of $\mathrm{A} \beta$ and $\mathrm{H}_{2} \mathrm{O}_{2}$ hydroxyl radicals that are present in $\mathrm{AD}$. In this study, diffuse vacuolization of the gray substance (malacia) and intense gliosis was observed in group treated, i.e., intense neuronal death from lack of oxygen and glucose and the presence of diffuse senile plaques. The results suggest a reduction in tissue damage in hippocampal structures caused by the pro-inflammatory cytokines released during apoptosis. This damaged tissue is subjected to the effect of the $\beta$-amiloid 25-35 peptide in the group receiving treatment with the EGb 761 extract.

Heneka and O'Banion [28] report that, in addition to glial activation, the neuroinflammatory component present in $\mathrm{AD}$ is characterized by a local acute response phase mediated by cytokines, activation of the complement system, release of glutamate, and induction of inflammatory enzymes. Increase in oxide nitric synthase (iNOS) and cyclooxygenase-2 (COX-2) result in increase in the generation of nitric oxide (NO) and ROS. This study corroborates the findings of Heneka and O'Banion, who report the effects of Gingko Biloba in reducing proinflammatory cytokines and subsequent increase in anti-inflammatory cytokines.

Williams et al. [15] showed that EGb 761 could significantly modulate synaptic plasticity in aged rats by the glutaminergic system, both in chronic and acute treatment. In the present study, improvement in spatial memory was observed in the animals treated with EGB761,

\section{Locomotion in the Water Maze}

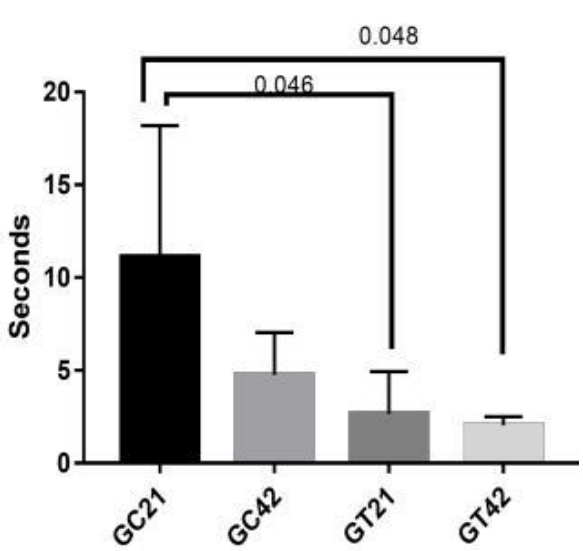

Figure 3: Average values of the range of locomotion in the Open Field and Morris Water Maze tests. 

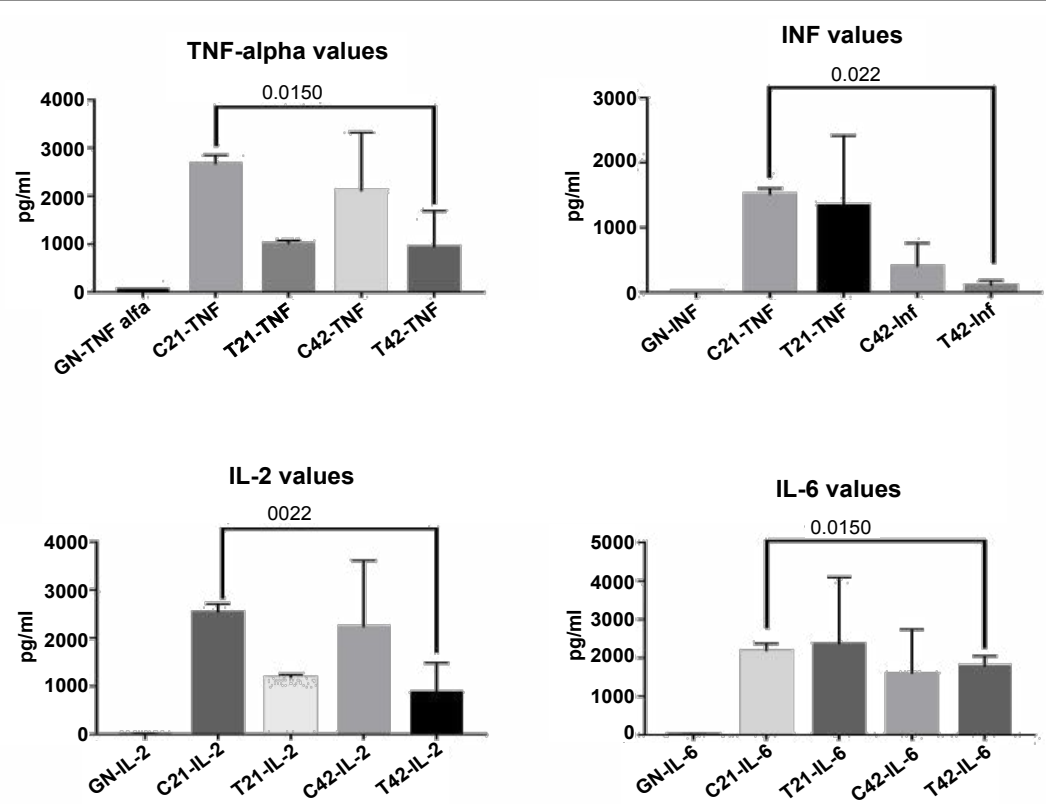

Figure 4: Average values in the Th1 system for proinflammatory interleukins in the 21 and 42 days treated groups.

\section{IL-4 values}

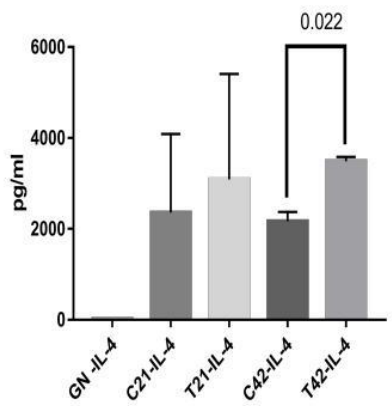

IL-10 values

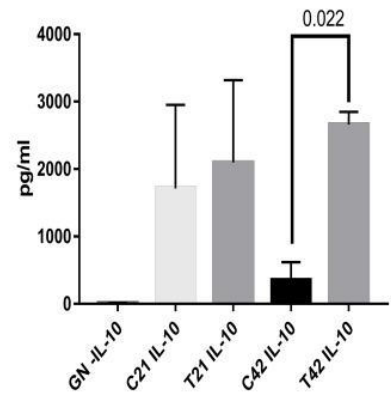

Figure 5: Average values in the Th2 system for the anti-inflammatory IL-4 and IL10 interleukins.

supporting the results of the aforementioned study that EGB761 acts on the glutaminergic system improving synaptic functions.

Pagliarone and Sforcin [29] reported that the IL-6 and IL-10 interleukins are produced by microglia activation and IL-10 acts inhibiting IL-6 and its receptor. The increase in production of inflammatory cytokines may result in an increased inflammatory response by immune and brain cells and may lead to a progression of neurodegenerative diseases.

In the present study, a significant difference was observed between IL-10 and INF-y in the C21 group and T21 and T42 groups while the statistical relationships of IL-10 with IL-6 did not achieve significantly different results. The influence of IL-10 on IL- 6 did not produce sufficient immune responses to sustain a balance in the inflammatory process.

Ching-Hsiang et al. [30] found a significant decrease in IL-6 levels with continuous GB treatment for eight weeks, resulting in antiinflammatory and antioxidant action. Meanwhile, IL-6 produced by several cell types, including endothelial, microglia, neurons, platelets,

leukocytes, and fibroblasts cells, is shown as an important regulator of neuroinflammation in neurons and astrocytes.

According to Zhao et al. [31] IL-10 is known for its antiinflammatory action and ability to inhibit pro-inflammatory cytokines. The reduction of IL-10 may indicate disorders of immunity and acute inflammation. Increased IL-10 levels can modulate abnormal immunity, inhibit inflammation, and promote tissue restoration.

According to Junior et al. [32] many of the protective effects of the CNS associated with the chronic use of EGB are related to the presence of terpenes and flavonoids constituents with antioxidant and antiinflammatory properties.

The present study demonstrated that animal with the AD-induced neuronal lesion and treated with Ginkgo biloba showed a reduction in the levels of pro-inflammatory cytokines and consequent reduction of the inflammatory response.

Davis and Laroche [33] report that the reduction in locomotion can be an adaptation of the animal to a disease state called Sickness Behavior: the reduction or loss in IL-10 production leads to behavior with reduced spatial exploration and social activity and reduced food intake. In the present study, although IL-10 levels are high when compared with other cytokines, the animals did not reduce their movements and showed no change in behavior.

Based on a quantitative analysis of the literature, little effect on cognitive function in $\mathrm{AD}$ is observed when $\mathrm{EGb} 761$ extract is supplemented for 3 to 6 months at doses between 120 and $240 \mathrm{mg}$. Petkov et al. (2003) demonstrated that the administration of leaf extracts (GK 501) and roots (PHL-007 010) of Ginkgo biloba or their combination improved learning and memory processes, which suggests that the neurotransmission dopaminergic system is involved in the behavioral effects promoted by these components, corroborating the findings in our study.

Cruz et al. [34] reported that the data on this subject are still limited and inconsistent because it involves many variables such as dose, duration of administration, age, individual differences in the level of 
Citation: Salgado ASI, Eltchechem CL, Kerppers II, Silva Pereira MC, Suckow PT, et al. (2017) Flow Cytometry Analysis of Pro- and Anti-inflammatory Cytokines in Alzheimer's Disease Model Treated with Ginkgo biloba. J Biosens Bioelectron 8: 241. doi: 10.4172/2155-6210.1000241

cognitive function, testing methodology, and others, which hinders the determination of effects on behavioral, cognitive, and functional measures as well as on the scales used for clinical assessment of the disease stage.

\section{Conclusion}

EGb 761 was shown to be effective in reducing serum levels of pro-inflammatory cytokines, promoting a possible reduction in the inflammatory process generated by AD.

\section{Conflict of Interest}

The authors have no conflicts of interest to declare.

\section{References}

1. Troncoso JC, Cataldo AM, Nixon RA, Barnett JL, Lee MK, et al. (1998) Neuropathology of preclinical and clinical late-onset Alzheimer's disease. Ann Neurol 43: 673-676.

2. Sandberg G, Stewart W, Smialek J, Trancoso JC (2001) The prevalence of the Neuropathological lesions of Alzheimer's disease is independent of race and Gender. Neurobiol Aging 22: 169-175.

3. Lartelli I, Converso MER (2007) Characterization and analysis of mental and functional status of institutionalized elderly people in long-term public institutions. J Bras Psychiatrist 56: 267-272.

4. Lindeboom J, Weinstein H (2004) Neuropsychology of Cognitive ageing minimal cognitive impairment, Alzheimer's disease, and vascular cognitive impairment. Eur J Pharmacol 490: 83-86.

5. Terry RD, Katzman R (1983) Senile dementia of the Alzheimer type. Ann Neurol 14: 497-506.

6. Whitehouse PJ, Struble RG, Hedreen JC, Clark AW, Price DL (1985) Alzheimer's disease and Related dementias: selective involvement of specific neuronal Systems. CRC Crit Rev Clin Neurobiol 1: 319-339.

7. Sisodia SS, Martin LJ, Walker LC, Borcjelt DR, Price DL (1995) Cellular and molecular biology of Alzheimer's disease and animal models. Neuroimaging Clin N Am 5: 59-68.

8. Hardy J, Selkoe DJ (2002) The amyloid hypothesis of Alzheimer's disease: Progress and problems on the road to therapeutics. Science 297: 353-356.

9. Mattson MP (2004) Pathways towards and away from Alzheimer's disease. Nature 430: 631-639.

10. De La Torre JC (2002) Alzheimer disease as a vascular disorder: nosological evidence. Stroke 33: 11521162.

11. Perry EK, Pickering AT, Wang WW, Houghton PJ, Perry NSL (1999) Medicinal plants and Alzheimer's disease: from ethnobotany to phytotherapy. J Pharm Pharmacol 51: 527-534.

12. Yang M, Xu DD, Zhang Y, Liu X, Hoeven R, Cho WCS (2014) A systematic review on natural medicines for the prevention and treatment of Alzheimer's disease with meta-analyses of intervention effect of Ginkgo. Am J Chin Med 42: $505-521$

13. Le Bars PL, Katz MM, Berman N, Itil TM, Freedman AM, et al. (1997) A placebo-controlled, double-blind, randomized trial of an extract of Ginkgo biloba for dementia. North american EGB study group. JAMA 278: 1327-1332.

14. Petkov VD, Belcheva S, Petkov VV (2003) Behavioral effects OS Ginkgo biloba L., Panax ginseng C.A. Mey and Gincosan. Am J Chin Med 31: 841-855

15. Williamns B, Watanabe CMH, Schultz PJ, Rimbach G, Krucker T (2004) Agerelated effects of Ginkgo biloba extract on synaptic plasticity and excitability. Neurobiol Aging 25: 955-962.

16. Bastianetto S, Ramassamy C, Doré S, Christen Y, Poirier J, et al. (2000) The Ginkgo biloba extract (EGb 761) protects hippocampal neurons against cell death induced by beta amyloid. Eur J Neurosci 12: 1882-1890.
17. Freitas MB, Brilhante OM, Almeida LM (2001) Importance of water analysis for public health in two regions of the State of Rio de Janeiro: focus for fecal coliforms, nitrate and aluminum. Cadernos de Saúde Pública 17: 651-659.

18. Allen RG, Tresini EM (2000) Oxidative stress and gene regulation. Free Radic Biol Med 28: 463-499.

19. Vieira S, Hossne WS (2001) Metodologia científica para a área da saúde editora campus, são Paulo p: 295.

20. Pereira MG (1995) Epidemiologia: Teoria e prática. Rio de Janeiro: Guanabara p: 355.

21. Freir DB, Costello DA (2003) A beta 25-35-induced depression of long-term potentiation in area ca1 in vivo and in vitro is attenuated by verapamil. $J$ Neurophysiol 89: 3061-3069.

22. Kamerman $P$, Koller A, Loram L (2007) Postoperative administration of the analgesic tramadol, but not the selective cyclooxygenase-2 inhibitor parecoxib, abolishes postoperative hyperalgesia in a new model of postoperative pain in rats. Pharmacology 80: 244-248.

23. Paxinos G, Watson C (1998) The rat brain in stereotaxic coordinates. (4thedn), Academic press, San diego.

24. Vigi FAB, Miranda LS, Caixeta ARP, Arantes RME, Miranda AS, et al. (2011) Effects of cognitive spatial training associated to hippocampal high oncentration of beta-amyloide on morphologic, immunologic and neurochemistry parameters. In: excitotoxicity and neuroprotection spring school (enss). Excitotoxicity and neuroprotection spring school abstract book 1: 46-55.

25. Wlash RN, Cummins RA (1976) The Open-Field test: A critical review. Psychol Bull 83: 482-504.

26. Ni Y, Zhao B, Hou J, Xin W (1996) Preventive effect of Ginkgo biloba extract on apoptosis in rat cerebellar neuronal cells induced by hydroxyl radicals. Neurosci Lett 214: 115-118.

27. Chen J, Herrup K (2012) Glutamine acts as a neuroprotectant against DNA damage, beta-amyloid and $\mathrm{H} 2 \mathrm{O} 2$-induced stress. Plos One 7: e33177.

28. Heneka MT, O’Banion MH (2007) Inflammatory processes in Alzheimer's disease. J Neuroimmunol 69: 184-193.

29. Pagliarone AC, Sforcin JM (2009) Stress: review about the effects on the immune system. Biosaúde 11: 57-90.

30. Ching-Hsiang $\mathrm{L}$, Chiao-Wen $\mathrm{H}$, Nan-Fu C, Wen-Sheng $\mathrm{L}, \mathrm{Ya}-\mathrm{Fen} \mathrm{H}$, et al. (2012) In vivo effects of Ginkgo biloba extract on Interleukin-6 cytokine levels in patients with neurological disorders. Indian Journal of Pharmacology 44: 118-128.

31. Zhao J, Su J, Chen A, Yuan H, Lui L, et al. (2011) Effect of ginkgo leaf parenteral solution on blood and cochlea antioxidant and immunity indexes in OM rats. Molecules 16: 10433-10442.

32. Junior CV, Bolzani VS, Furlan M, Fraga CAM, Barreiro EJ (2004) Natura products as candidates for useful drugs in the treatment of Alzheimer's disease. New Chemistry 27: 655-660.

33. Davis S, Laroche S (2003) What can rodent models tell us about cognitive decline in Alzheimer's disease. Mol Neurobiol 27: 249-276

34. Cruz JG, Silva AC, Lima DD, Dal Magro DD, Muller DF, et al. (2010) Efeitos do extrato de Ginkgo biloba (EGb 761) e da natação repetida sobre a memória, ansiedade e atividade motora de ratos. Rev Ciênc Farm Básica 31: 149-155. 